\title{
Somatostatin Analogue Scintigraphy
}

\author{
A Simple and Sensitive Method for the In Vivo Visualization \\ of Merkel Cell Tumors and Their Metastases
}

Dirk J. Kwekkeboom, MD; Anneke M. Hoff, MD; Steven W. J. Lamberts, MD; H. Yoe Oei, MD; Eric P. Krenning, MD

\begin{abstract}
- Background-Trabecular carcinomas of the skin, or Merkel cell tumors, are aggressive neoplasms that tend to occur in sun-exposed skin. These tumors frequently metastasize and, despite therapy, the number of disease-related deaths is high. Ultrastructurally and immunocytochemically, the majority of these tumors have neuroendocrine characteristics. Recently, we described the in vivo visualization of various neuroendocrine tumors after injection of a radiolabeled somatostatin analogue (octreotide). In this study, we report the results of scintigraphy with radioactive-labeled somatostatin analogues in five patients with Merkel cell tumors.

Observations. - In all four patients in whom tumor was detected using computed tomographic scanning and ultrasound, the tumor sites were also demonstrated on octreotide scintigrams. In one patient, a tumor with a diameter that was smaller than $0.5 \mathrm{~cm}$ could not be detected with octreotide scintigraphy, computed tomography, or ultrasound. Using octreotide scintigraphy we found presumed tumor spots in two patients that were not evident when other techniques were used.

Conclusions.-Octreotide scintigraphy has an equal or even greater sensitivity than computed tomography and ultrasound for detecting Merkel cell tumors and their metastases. Establishing the spread of the disease in this way may ensure an optimal choice of treatment in patients with this type of tumor.
\end{abstract}

(Arch Dermatol. 1992;128:818-821)

Trabecular carcinomas of the skin, or Merkel cell tu1 mors, first described in 1972, ${ }^{1}$ are agressive neoplasms that tend to occur on sun-exposed skin. A high

\footnotetext{
Accepted for publication October 1, 1991 .

From the Departments of Medicine (Drs Kwekkeboom, Lamberts, and Krenning) and Nuclear Medicine (Drs Kwekkeboom, Lamberts, Oei, and Krenning), University Hospital Dijkzigt (Drs Kwekkeboom, Lamberts, Oei, and Krenning), and the Department of Medicine, Dr Daniël den Hoed Kliniek (Dr Hoff), Rotterdam, The Netherlands. Reprints not available.
}

incidence of spread to regional lymph nodes ( $45 \%$ to $91 \%$ ) and of distant metastasis (18\% to $52 \%$ ) has been reported $^{2-8}$ (for a review see reference 9). Primary treatment of these tumors is often limited to local excision. Lymph node dissection and postoperative radiotherapy can be used to treat larger lesions, whereas recurrences and distant metastases are often treated with chemotherapy and/or radiotherapy. Nevertheless, depending on the time of follow-up, the incidence of disease-related death is as high as $35 \%$ to $47 \%$ in patients with Merkel cell tumors., ${ }^{3,7,8}$ Early assessment of the dissemination of the process seems therefore justified, as this might change the therapeutic approach to these tumors.

In the recent literature, several reports have stressed the neuroendocrine characteristics of Merkel cell tumors: ultrastructurally they contain secretion granules, ${ }^{6,7}$ and immunocytochemical stains are positive for neuron-specific enolase (NSE) in the majority of cases..$^{10-13}$ Recently, we described the in vivo visualization of various neuroendocrine tumors after injection of a somatostatin analogue (octreotide) coupled to iodine $123 . .^{14-16}$ The neuroendocrine features of Merkel cell tumors prompted us to investigate whether somatostatin receptors are also present on this type of tumor, and whether this skin carcinoma and its metastases can be visualized in vivo using octreotide scintigraphy.

\section{PATIENTS AND METHODS}

\section{Patients}

We studied five patients with Merkel cell tumors in whom iodine $123\left({ }^{12: 3} \mathrm{I}\right)$ - or indium $111\left({ }^{111} \mathrm{In}\right.$ )-labeled octreotide scintigraphy was performed. Histologic confirmation of the lesion was obtained in every patient. All patients gave informed consent to participate in the study, which was approved by the ethics committee of our hospital. 


\section{Methods}

The somatostatin analogues tyrosine $3\left(\mathrm{Tyr}^{3}\right)$-octreotide (204-090) and diethylenetriamine penta-acetic acid-Dphenylalanine 1 (DTPA-D-Phe ${ }^{1}$ )-octreotide (215-811) were obtained commercially (Sandoz, Basel, Switzerland). Tyrosine 3-octreotide was iodinated as described previously ${ }^{17}$; DTPA-D-Phe ${ }^{1}$-octreotide was coupled to ${ }^{111} \mathrm{In}$ as described elsewhere. ${ }^{18}$

The in vivo visualization of somatostatin receptor-positive tumors after injection of ${ }^{123} \mathrm{I}^{-} \mathrm{Tyr}^{3}$-octreotide, a radiolabeled somatostatin analogue, has been described previously. ${ }^{14-16}$ Drawbacks of this in vivo receptor imaging technique are the limited availability of chemically pure ${ }^{123} \mathrm{I}$ and the high abdominal background of radioactivity, caused by principal clearance of this analogue via the liver. ${ }^{19}$ Therefore, an ${ }^{111}$ Inlabeled somatostatin analogue has been developed. Because of its relatively long, effective half-life, ${ }^{111}$ In-octreotide is a radionuclide-coupled somatostatin analogue that can be used to visualize somatostatin receptor-bearing tumors efficiently after 24 hours, when interfering background radioactivity is minimized by renal clearance. ${ }^{19}$

Planar images were obtained with a large-field-of-view gamma camera (Counterbalance 3700, Siemens Gammason- ics, Erlangen, Germany), equipped with a $190 \mathrm{keV}$ parallelhole collimator. Static images were obtained 4 and 24 hours after injection of the ${ }^{123}$ I-coupled somatostatin analogue, and 24 hours after injection of the ${ }^{111}$ In-coupled somatostatin analogue, respectively, because the background radioactivity at that time is low. To define the tumors as visualized during this scanning procedure, we used a simple yes-or-no system.

\section{RESULTS}

Patient data and results of octreotide scintigraphy are summarized in the Table. In patients 3 and $5,{ }^{123} \mathrm{I}$ Tyr ${ }^{3}$-octreotide ( 565 to $570 \mathrm{MBq}$ ) was injected, and in the other patients, ${ }^{111}$ In-DTPA-octreotide (262 to 328 $\mathrm{MBq}$ ) was injected. Case reports and the outcomes of visualization techniques are listed below.

Patient 1 had her right little finger amputated 2 years previously because of a trabecular carcinoma of the skin. Now the tumor had recurred at the site of the amputation. At physical examination, tumor was also suspected at the right elbow. In addition, the patient had an enlarged lymph node in the right axilla and her

\begin{tabular}{|c|c|c|}
\hline \multicolumn{3}{|c|}{ Patient Data and Results of Octreotide Scintigraphy } \\
\hline Patient No./Sex/Age, y & Tumor Sites & Sites on Octreotide Scintigraphy \\
\hline $1 / F / 53$ & Finger, elbow, axilla, liver & Finger, forearm, elbow, axilla, lung hilum \\
\hline $2 / \mathrm{M} / 49$ & Oropharynx & None \\
\hline $3 / \mathrm{M} / 63$ & Sinus and orbita, abdomen & Sinus and orbita, abdomen \\
\hline $4 / \mathrm{M} / 46$ & Supraclavicular lymph nodes & Supraclavicular spots \\
\hline $5 / \mathrm{M} / 79$ & Head & Head and parotic region \\
\hline
\end{tabular}

Fig 1.-Scintigraphy of the anterior skull of patient 3, 24 hours after injection of iodine 123-tyrosine 3-octreotide. Th indicates thyroid; $T$, tumor in the left orbita and sinuses.

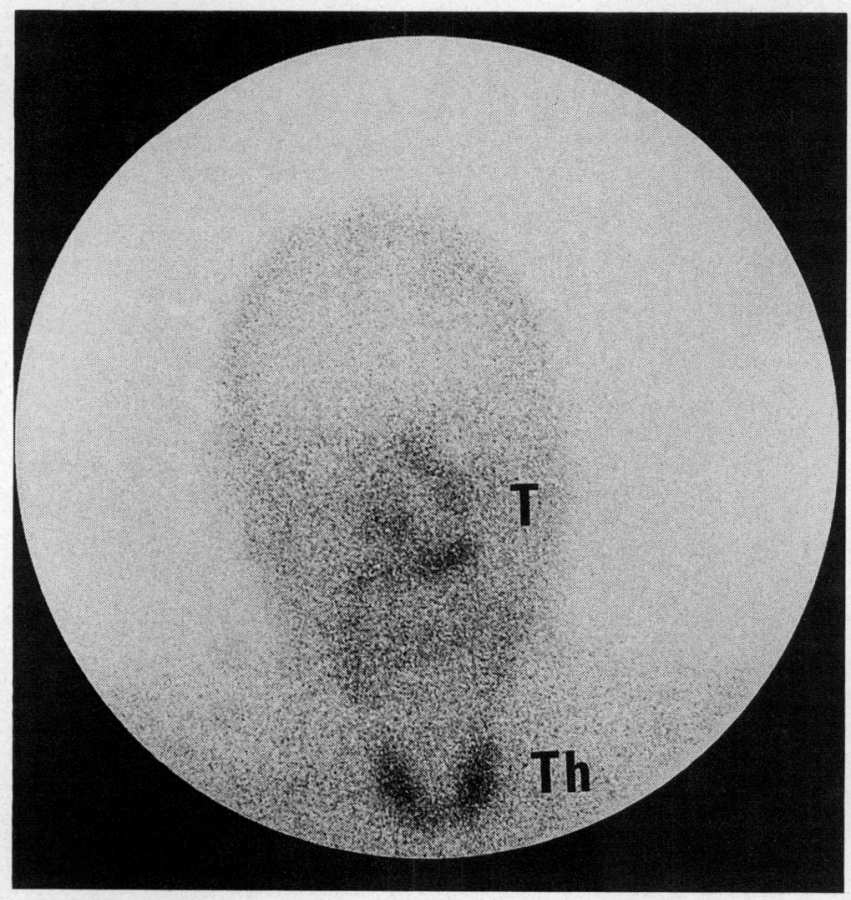

Arch Dermatol-Vol 128, June 1992
Fig 2.- Scintigraphy of the head and neck of patient 5,24 hours after injection of iodine 123-tyrosine 3-octreotide. T indicates primary tumor and spots in the parotic region. Note the physiologic accumulation in the pituitary, centrally in the skull.



Octreotide Scintigraphy-Kwekkeboom et al $\mathbf{8 1 9}$ 
liver was enlarged. Computed tomography of the thorax and abdomen showed multiple small metastases in the liver. A biopsy specimen of the lesion on the elbow contained a small-cell tumor, which was diagnosed as Merkel cell carcinoma. Stains were negative for NSE and chromogranin. Octreotide scintigraphy showed accumulation of radioactivity at the site of the primary tumor; stringlike spots in the right hand, forearm, elbow, and axilla; and a spot in the right pulmonary hilum. The distribution of radioactivity in the liver showed no irregularities. The patient was treated with chemotherapy and had a complete remission after 3 months. On octreotide scanning at this time, the sites of abnormal radioactive accumulation had disappeared.

Patient 2 had undergone an excision of a trabecular carcinoma of the buttock 2 years previously. An enlarged inguinal lymph node that had appeared 5 months later had also been removed. Both tumors were NSE positive. At the present time, the patient had complaints of swallowing. Computed tomography of the pharynx and abdomen, ultrasound of the neck, and octreotide scintigraphy revealed no abnormalities. At inspection of the pharynx, however, a small exophytic tumor with a diameter of less than $0.5 \mathrm{~cm}$ was seen. Histologic examination of the biopsy specimen and positive stains for NSE confirmed the diagnosis of Merkel cell tumor.

Patient 3 had a tumor of the lower eyelid removed 3.5 years previously. Two irradical reexcisions of the recurring tumor ensued. At that time, the tumor was diagnosed as a basal cell carcinoma. When the tumor recurred half a year later, it was diagnosed as an NSEand chromogranin-positive Merkel cell tumor. Radiotherapy resulted in a complete remission. At the present time, the patient had pain in the left eye, which had protruded. Ultrasound revealed enlarged lymph nodes in the neck and abdomen. The biopsy specimens of these lymph nodes were tumor positive. A debulking operation of the tumor in the sinuses and orbita and lymph node dissection of the neck were performed. Two months later the tumor rest in the left eye and sinuses was visible on computed tomographic scan and octreotide scintigrams (Fig 1). Fifteen minutes after injection of ${ }^{123} \mathrm{I}-\mathrm{Ty} \mathrm{r}^{3}$-octreotide, an abnormal accumulation of radioactivity was noted in the upper abdomen. This had disappeared on the scintigrams obtained 24 hours after injection. Eleven months later, the patient died of tumor growth in the abdomen.

In patient 4, a chromogranin-positive trabecular carcinoma of the neck and a recurrent tumor at the same spot were excised 14 and 4 months, respectively, before octreotide scintigraphy was performed. A lymph node metastasis in the neck was removed 1 month before scintigraphy was performed. At physical examination, two mobile supraclavicular lymph nodes were observed. Octreotide scintigraphy revealed accumulation of radioactivity at these sites.

Patient 5 suffered from chronic lymphatic leukemia and a recurrence of an NSE-positive Merkel cell tumor of the forehead. Five months previously, the trabecular carcinoma had been partially removed. Before scintigraphy, a biopsy was performed on a tumor that contained a preauricular lymph node. Computed tomography of the head showed a soft-tissue tumor. Octreotide scintigraphy revealed spots on the site of the tumor and two spots behind the ear, suggestive of metastases (Fig 2). At physical examination 1 month later, enlarged lymph nodes were found behind the ear.

\section{COMMENT}

Local recurrence and metastasis after initial treatment of Merkel cell tumors are frequent..$^{1-9,20-23}$ In our series, distant spread after initial surgical removal of the tumor occurred in all five patients. Also, multifocality of the tumor at or about the time of diagnosis is not infrequent. $8,24,25$ Therefore, accurate localization and staging of the tumor should be performed in every patient, as this might influence the choice of treatment: excision, radiotherapy, chemotherapy, or combinations of these. In vivo visualization of these tumors using octreotide scintigraphy may be of help in this respect, as will be discussed below.

In all four patients in whom tumor was indicated by computed tomography and ultrasound, the tumor sites were also demonstrated on octreotide scintigrams. In one patient, no tumor could be detected with octreotide scintigraphy, CT, or ultrasound. The lesion was probably too small to be detected with any of these techniques. Multiple small metastases in the liver of one patient were not observed on octreotide scintigrams, perhaps because the lesions were too small to be detected or because they accumulated about as much radioactivity as did the normal liver tissue. Unfortunately, technetium $99 \mathrm{~m}$ colloid scintigraphy was not performed in this patient, so this problem could not be addressed. Using octreotide scintigraphy we found presumed tumor spots that were not detected by other techniques in two patients (patients 1 and 5). In one of these patients (No.5), enlarged lymph nodes, probably caused by tumor metastases, developed at the site of the spots that had been observed on the octreotide scintigrams 1 month previously. In four patients, the lesions demonstrated on CT and ultrasound scans coincided with spots of accumulation of labeled octreotide. In one patient, sites of abnormal accumulation of radioactivity that were present before treatment had disappeared when a complete remission after chemotherapy had been reached.

Merkel cell carcinoma, also termed neuroendocrine carcinoma of the skin, ${ }^{3}$ or cutaneous apudoma, ${ }^{21}$ is a rare skin tumor. Electron microscopy may reveal secretion granules in these tumors, ${ }^{6,7}$ and staining for NSE is positive in the majority of cases. ${ }^{10-13}$ Our data suggest that Merkel cell tumors, like other neuroendocrine tumors that can be visualized using in vivo octreotide scintigraphy, ie, carcinoids, paragangliomas, and endocrine pancreatic tumors, ${ }^{14-16}$ contain binding sites for somatostatin. Whether other somatostatin analogues coupled to radiotherapeutical isotopes can be used in the future treatment of disseminated Merkel cell tumors is at this moment speculative.

Regional lymph node dissection and radiotherapy are generally not applied for Merkel cell tumors that have not disseminated. ${ }^{3}$ However, the metastatic po- 
tential of these carcinomas mandates that an early and accurate staging be made. From our data we conclude that octreotide scintigraphy has an equal or greater sensitivity for detecting Merkel cell tumors and their metastases than do CT scanning and ultrasound. If octreotide scintigraphy were performed in patients with Merkel cell tumors, the sites of abnormal accumulation of radioactivity could thereafter be visualized using CT scanning or ultrasound, and then undergo biopsy. Establishing the extent of the disease in this way may ensure an optimal choice of treatment for these tumors.

\section{References}

1. Toker C. Trabecular carcinoma of the skin. Arch Dermatol. 1972;105:107-110.

2. Meland NB, Jackson IT. Merkel cell tumor: diagnosis, prognosis, and management. Plast Reconstr Surg. 1986;77:632-638.

3. Hitchcock CL, Bland KI, Laney RG III, Franzini D, Harris B, Copeland EM III. Neuroendocrine (Merkel cell) carcinoma of the skin. Ann Surg. 1988;207:201-207.

4. Raaf JH, Urmacher C, Knapper WK, Shiu MH, Cheng EWK. Trabecular (Merkel cell) carcinoma of the skin. Cancer. 1986;57:178182.

5. Pacella J, Ashby M, Ainslie J, Minty C. The role of radiotherapy in the management of primary cutaneous neuroendocrine tumors (Merkel cell or trabecular carcinoma): experience at the Peter MacCallum Cancer Institute (Melbourne, Australia). Int J Radiat Oncol Biol Phys. 1988;14:1077-1084.

6. Wick MR, Goellner JR, Scheithauer BW, Thomas JR III, Sanchez NP, Schroeter AL. Primary neuroendocrine carcinomas of the skin (Merkel cell tumors). Am J Clin Pathol. 1983;79:6-13.

7. Sibley RK, Dehner LP, Rosai J. Primary neuroendocrine (Merkel cell?) carcinoma of the skin, I: a clinicopathologic and ultrastructural study of 43 cases. Am J Surg Pathol. 1985;9:95-108.

8. Silva EG, Mackay B, Goepfert H, Burgess MA, Fields RS. Endocrine carcinoma of the skin (Merkel cell carcinoma). Pathol Annu. 1984;19:1-30.

9. Knox SJ, Kapp DS: Hyperthermia and radiation therapy in the treatment of recurrent Merkel cell tumors. Cancer. 1988;62:14791486.

10. Sibley RK, Dahl D. Primary neuroendocrine (Merkel cell?) carcinoma of the skin, II: an immunocytochemical study of 21 cases.
Am J Surg Pathol. 1985;9:109-116.

11. Gu J, Polak JM, van Noorden S, Pearse AGE, Marangos PJ, Azzopardi JG. Immunostaining of neuron-specific enolase as a diagnostic tool for Merkel cell tumors. Cancer. 1983;52:1039-1043.

12. Kirkham N, Isaacson P. Merkel cell carcinoma: a report of three cases with neurone-specifie enolase activity. Histopathology. 1983;7:251-259.

13. Warner TFCS, Uno H, Hafez GR, et al. Merkel cells and Merkel cell tumors: ultrastructure, immunocytochemistry and review of the literature. Cancer. 1983;52:238-245.

14. Krenning EP, Bakker WH, Breeman WAP, et al. Localisation of endocrine-related tumours with radioiodinated analogue of somatostatin. Lancet. 1989;1:242-244.

15. Lamberts SWJ, Bakker WH, Reubi JC, Krenning EP. Somatostatin receptor imaging in the localization of endocrine tumors. $N$ Engl J Med. 1990;323:1246-1249.

16. Lamberts SWJ, Hofland LJ, van Koetsveld P, Reubi JC, Bakker WH, Krenning EP. Parallel in vivo and in vitro detection of functional somatostatin receptors in human endocrine pancreatic tumors: consequences with regard to diagnosis, localization, and therapy. J Clin Endocrinol Metab. 1990;71:566-574.

17. Bakker WH, Krenning EP, Breeman WA, et al. Receptor scintigraphy with a radioiodinated somatostatin analogue: radiolabeling, purification, biological activity and in vivo application in animals. J Nucl Med. 1990;31:1501-1509.

18. Bakker WH, Albert R, Bruns C, et al. ['1'In-DTPA-D-Phe ${ }^{1}$ octreotide, a potential radiopharmaceutical for imaging of somatostatin receptor-positive tumors: synthesis, radiolabeling and in vitro validation. Life Sci. 1991;49:1583-1591.

19. Bakker WH, Krenning EP, Reubi JC, et al. In vivo application of [ ${ }^{111}$ In-DTPA-D-Phe']-octreotide for detection of somatostatin receptor-positive tumors in rats. Life Sci. 1991;49:1593-1601.

20. George TK, di Sant'Agnese PA, Bennett JM. Chemotherapy for metastatic Merkel cell carcinoma. Cancer. 1985;56:1034-1038.

21. de Wolf-Peeters C, Marien K, Mebis J, Desmet V. A cutaneous APUDoma or Merkel cell tumor? Cancer. 1980;46:1810-1816.

22. Wynne CJ, Kearsley JH. Merkel cell tumor. Cancer. 1988;62: 28-31.

23. Taxy JB, Ettinger DS, Wharam MD. Primary small cell carcinoma of the skin. Cancer. 1980;46:2308-2311.

24. Abaci IF, Zak FG. Multicentric amyloid containing cutaneous trabecular carcinoma. $J$ Cutan Pathol. 1979;6:292-303.

25. Wick MR, Thomas JR III, Scheithauer BW, Jackson IT. Multifocal Merkel's cell tumors associated with a cutaneous dysplasia syndrome. Arch Dermatol. 1983;119:409-414. 